\section{Undetectable hemoglobin in a patient with chronic uterine bleeding}

DOI:10.2478/rrlm-2019-0035

\section{Dear Editor,}

Abnormal uterine bleeding in perimenopause is the commonest presenting complaint encountered in gynecology. This condition requires rapid diagnosis and treatment. In women with heavy or chronic bleeding, laboratory tests are very important for the diagnosis of anemia (1).

Severe anemia is frequent in women with voluminous or intracavitary myoma, resulting in urgent medical care or blood transfusion (2). Uterine fibroids are often associated with abnormal uterine bleeding. Symptomatic fibroids remain a common indication for hysterectomy in women who have completed their family (1).

We present the case of a 47-year-old woman who was referred to the Gynecology Department of Filantropia Clinical Hospital, Bucharest in August 2018 with chronic uterine bleeding, pale skin, fatigue, and tachycardia. Medical history revealed a chronic treatment with Euthyrox $125 \mathrm{mg} /$ day after a thyroidectomy for multinodular goiter. The patient presented to the emergency room independently, conscious with chronic excessive vaginal bleeding. Clinical examination revealed abdominal distension, with a voluminous irregular palpable mass, with increased consistency extending up to umbilical region. Transvaginal ultrasound examination revealed a voluminous leiomyoma 280/18mm and a left ovarian cyst $70 / 60 \mathrm{~mm}$. Complete blood count revealed undetectable hematocrit and undetectable hemoglobin $(\mathrm{Hb})$ (two determinations $-\mathrm{Hb}$ under detection level, erythrocyte indices could not be determined). Complete blood count was performed using Convergys X5 analyzer (Covergent Technologies, Colbe, Germany). $\mathrm{Hb}$ analysis was performed spectrophotometrically, with limit of detection of $1.3 \mathrm{~g} / \mathrm{dL}$. According to the manufacturers' instructions, the limit of detection for platelets was $10,000 / \mathrm{mm}^{3}$ and $40,000 / \mathrm{mm}^{3}$ for red blood cells. We proceeded with urgent blood transfusion and one unit of packed red blood was administered. The patient was admitted and monitored in the gynecology unit. Another blood sample was carried out in 3 hours after blood administration that revealed a microcytic hypochromic anemia with $\mathrm{Hb}$ of $3 \mathrm{~g} /$ $\mathrm{dL}$, average red blood cell size (MCV) of 78.5 and mean hemoglobin amount per red blood cell $(\mathrm{MCH})$ of $21.4 \mathrm{pg} / \mathrm{cell}$, hematocrit $11 \%$, white blood cells (WBC) $5,200 / \mu \mathrm{L}$, platelets (PLT) $102,000 / \mu \mathrm{L}$. Under these circumstances, we opted for another transfusion with 4 units of packed red blood, in order to improve the hematological status. After the second transfusion, the patients had $\mathrm{Hb}$ of $8.9 \mathrm{~g} / \mathrm{dL}, \mathrm{WBC} 13,700 / \mu \mathrm{L}$, hematocrit $28.7 \%$ and PLT $160,000 / \mu L$. Endometrial biopsy was performed and the patient was informed about the surgical treatment possibilities. Three weeks later, we performed in accordance with the patient decision, a total hysterectomy with bilateral salpingo-oophorectomy under general anesthesia. The histopathological examination showed multiple myomas and a simple endometrial hyperplasia. Our patient signed an informed consent.

We reported an extremely rare case of patient with undetectable haemoglobin due to uterine symptomatic myomas. Severe anaemia that is well tolerated $(<4 \mathrm{~g} / \mathrm{dL})$ is uncommon in patients with chronic bleeding $(3,4)$. Th literature only reports few cases of severe anemia in out-patients with different etiologies. Imaizumi et al. report- 
ed the case of a patient with $\mathrm{Hb}$ of $1.8 \mathrm{~g} / \mathrm{dL}$, from urinary bleeding, despite gastrointestinal bleeding, the most common cause of anemia (4$6)$.

Rob et al. report the case of a patient with $1.8 \mathrm{~g} / \mathrm{dL}$ due to a secondary colon cancer (7). Panse et al. presented the case of a patient with severe anemia $(\mathrm{Hb} 1.8 \mathrm{~g} / \mathrm{dL})$ from chronic uterine bleeding (8). Rapid treatment was necessary to improve hematological status.

The particularity of our case was the low value of hemoglobin due to chronic blood loss, in a patient with symptomatic multiple uterine myomas. Interestingly, the patient referred herself to the Gynecology Department with chronic uterine bleeding, pale skin, fatigue, and tachycardia. This case adds to previous three out-patients who survived with a $\mathrm{Hb}<2 \mathrm{~g} / \mathrm{dL}$.

Nicolae Gica1, Natalia Darii Plopa ${ }^{2 *}$, Ruxandra Cigaran ${ }^{1}$, Corina Mat' ${ }^{1}$, Anca Maria Panaitescu ${ }^{3}$, Gheorghe Peltecu ${ }^{3}$, Paul Balanescu ${ }^{4}$

\section{Filantropia Clinical Hospital Bucharest,} Romania

2. CHU Marie Curie, Charleroi, Belgium

3. Carol Davila University of Medicine and

Pharmacy; Bucharest, Romania

4. Colentina Clinical Hospital Bucharest, Romania

\section{Corresponding author}

Natalia Darii Plopa, e-mail: natalia.plopa-darii@chu-charleroi.be

Received: $14^{\text {th }}$ May 2019

Accepted: 20 ${ }^{\text {th }}$ September 2019

Published: $6^{\text {th }}$ October 2019

\section{Conflict of interest}

None to declare.

\section{Authors' contribution}

Conceptualization: NG, RC, AMP

Methodology: CM,GP, PB

Software: PB, NDP

Validation: GP, PB

Formal analysis: NG, CM

Investigation: AMP, RC

Resources: RC, NG

Data Curation: RC, NG, NDP, AMP

Writing - original draft preparation: $\mathrm{NG}, \mathrm{PB}$, NDP

Writing - review and editing: GP, AMP, CM

Visualization: PB, NG, NDP

Supervision: GP, AMP

Project administration: NG

Funding acquisition: All authors

\section{References}

1. Goldstein SR, Lumsden MA. Abnormal uterine bleeding in perimenopause. Climacteric. 2017 Oct;20(5):414420 DOI: $10.1080 / 13697137.2017 .1358921$

2. Cooke AG, McCavit TL, Buchanan GR, Powers JM, Iron Deficiency Anemia in Adolescents Presenting with Heavy Menstrual Bleeding, J Pediatr Adolesc Gynecol, 2017 Apr;30(2):247-250 DOI: 10.1016/j. jpag.2016.10.010

3. Padmakumar R, Pai M, Farish S, Rajeev J, Sanjeev T, Sreevalsan TV et al. Successful bowel surgery at hemoglobin $2 \mathrm{~g} / \mathrm{dL}$ without blood transfusion. World J Gastrointest Surg 2013 Aug;5(8):252-255 DOI: 10.4240/ wjgs.v5.i8.252

4. Imaizumi T, Yagi E, Ushijima K, Suzuki K, Terasaki H. A patient with a preoperative hemoglobin concentration of $1.8 \mathrm{~g} / \mathrm{dl}$ : how was the life-threatening anemia tolerated without any intensive care? J Anesth 1999;13(2):125-126 DOI: 10.1007/s005400050041

5. Navuluri R, Kang L, Patel J, Ha TV. Acute lower gas- 
trointestinal bleeding. Semin Intervent Radiol 2012 Sep;29(3):178-186. DOI: 10.1055/s-0032-1326926

6. Strate LL. Lower GI bleeding: epidemiology and diagnosis. Gastroenterol Clin North Am 2005 Dec;34(4):643-664 DOI: 10.1016/j.gtc.2005.08.007

7. Schmitt RE, Buckley CJ 2nd. Extreme anemia (he- moglobin $1.8 \mathrm{~g} / \mathrm{dL}$ )secondary to colon cancer. Proc (Bayl Univ Med Cent). 2016 Oct;29(4):393-394 DOI: 10.1080/08998280.2016.11929482

8. Panse K, Regn R, May J. Extreme Anemia (Hemoglobin $1.8 \mathrm{~g} / \mathrm{dL}$ ) Secondary to Abnormal Uterine Bleeding. Case Rep Obstet Gynecol. 2017 Dec 21:5179265 DOI: $10.1155 / 2017 / 5179265$ 